
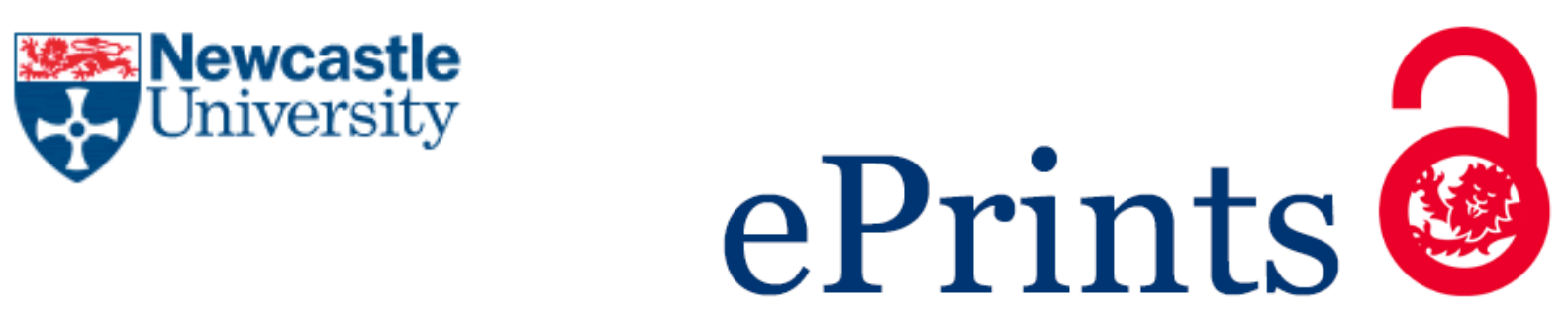

\author{
Bakar NS, Neely D, Avery P, Brown C, Daly AK, Kamali F. \\ Genetic and Clinical Factors Are Associated With Statin-Related Myotoxicity \\ of Moderate Severity: A Case-Control Study. \\ Clinical Pharmacology and Therapeutics 2017 \\ DOI: https://doi.org/10.1002/cpt.887
}

\title{
Copyright:
}

This is the peer reviewed version of the article, which has been published in final form at https://doi.org/10.1002/cpt.887. This article may be used for non-commercial purposes in accordance with Wiley Terms and Conditions for Self-Archiving.

DOI link to article:

https://doi.org/10.1002/cpt.887

Date deposited:

$22 / 12 / 2017$

Embargo release date:

22 September 2018 


\section{Genetic and clinical factors are associated with statin- related myotoxicity of moderate severity: a case-control study}

Brief title: genetics, sex and statin related myalgia

*Nur Salwani Bakar¹, PhD, Dermot Neely², MD, Peter Avery³, PhD, Colin Brown ${ }^{4}$, PhD, Ann K. Daly ${ }^{1}$, PhD, Farhad Kamali ${ }^{1}$, PhD.

${ }^{1}$ Institute of Cellular Medicine, Newcastle University, UK; ${ }^{2}$ Department of Clinical Biochemistry, Newcastle upon Tyne Hospitals Foundation Trust, UK; ${ }^{3}$ School of Mathematics and Statistics, Newcastle University, ${ }^{4}$ Institute for Cell and Molecular Biosciences, Newcastle University, UK.

*Current address: School of Health Sciences, Universiti Sains Malaysia, Malaysia

Word count: 3731 (excluding abstract, references, tables and figure legends)

No of figures: 1

No of tables: 6

No of references: 50

Address for correspondence: Farhad Kamali, The Medical School, Institute of Cellular Medicine, Newcastle University, Newcastle upon Tyne, NE2 4HH, UK.

E.mail: farhad.kamali@ncl.ac.uk.

Tel: +44 1912088043

KEY WORDS: Statins, hypercholesterolemia, cardiovascular disease, muscle toxicity, genetics, SLCO1B1. 


\section{ABSTRACT}

We evaluated the contribution of patient specific clinical and genetic factors to statinrelated muscle toxicity (SRM) without significant creatine kinase elevation (125 cases related to simvastatin or atorvastatin and 481 controls). The association between 12 SNPs in nine candidate genes and clinical factors with SRM was evaluated. Of the 12 SNPs genotyped, only rs4149056 in SLCO1B1 was associated with SRM in univariate analysis (with any statin, $\mathrm{OR}=1.73,95 \% \mathrm{Cl}=1.14-2.62, \mathrm{P}=0.010)$ and this association was influenced by $\operatorname{sex}(\mathrm{P}=0.006)$ and BMI $(P=0.02)$. In multivariate and binary logistic regression analyses, SLCO1B1 rs4149056 genotype $(\mathrm{OR}=1.66,95 \% \mathrm{Cl}: 1.08-2.54, \mathrm{P}=0.014)$ and $\operatorname{sex}(\mathrm{OR}=1.72,95 \% \mathrm{Cl}=1.15-$ $2.59, \mathrm{P}=0.006$ ) were independently associated with muscle toxicity related to statin treatment. Patient-specific genetic and clinical factors associated with increased systemic exposure to statins are implicated in the full spectrum of SRM, including myalgia in addition to severe myopathy. 


\section{INTRODUCTION}

Although statins are generally well tolerated, statin-associated side-effects are a common problem in routine clinical practice, leading to dose reduction, non-adherence or discontinuation of therapy, with consequent poor control of LDL-cholesterol and increased risk of preventable cardiovascular morbidity and mortality (1). Statin-associated musculoskeletal symptoms (SAMS) without significant elevation of creatine kinase is the most common adverse event leading to discontinuation of therapy (2). However, therapy can be restored in the majority of statin-intolerant patients when re-challenged (3). Indeed, in large clinical trials, minor muscle symptoms occur at similar frequency, regardless of allocation to statin or placebo suggesting that in most patients, SAMS are not of pharmacological origin $(4,5)$. Conversely, true statin-related muscle toxicity (SRM), with characteristic symptoms which resolve quickly on discontinuation of therapy and recur with re-challenge, is demonstrated in only a minority of SAMS cases under double-blind conditions $(6,7)$. The phenotype of SRM ranges from tolerable myalgia to intolerable muscle pain and weakness with elevation of creatine kinase (CK) due to breakdown of muscle tissue mandating immediate withdrawal of statin therapy (8). The graded classification proposed by Alfirevic et. al. (8) defines this spectrum on a scale of 0-6 according to the severity of symptoms, CK elevation and end organ damage. Although more severe forms of muscle toxicity, such as myopathy and rhabdomyolysis (SRM4-5), are infrequent even at higher statin doses $(8,9)$, clinicians considering re-challenge in patients intolerant of the high intensity statin regimes recommended for effective cardiovascular prevention face a difficult decision - how to distinguish patients with minor muscle symptoms of non-pharmacological origin from those with "true SRM" of moderate severity (SRM 2-3) who are at risk of progression to more severe myopathy, and in whom the high cost, non-statin alternative therapies such as PSCK9 inhibitors may be justified. 
There is consistent evidence that patient-specific clinical factors, such as advanced age (10), female sex $(11,12)$, low body mass (13), hepatic and renal dysfunction (14) and drug- drug interactions (15), contribute to SRM (16). There is also compelling evidence that genetic factors, including those that influence statin disposition and localization in skeletal muscle increase the risk of SRM in susceptible individuals (16). The best genetic predictor for severe forms of statin-related myopathy is the rs 4149056 polymorphism in the SLCO1B1 gene, which codes for the organic anion-transporting polypeptide OATP1B1 (9). The existence of an association between SLCO1B1 rs4149056 and simvastatin-induced myopathy has a wellestablished pharmacokinetic basis (17) and has been confirmed in clinical studies by several investigators (18-21) but is clearly demonstrated only at higher doses and when CK elevation is included in the definition of $\operatorname{SRM}(18,22)$ but not at lower doses of statins or milder SRM(23). It is less clear whether this genetic variant is a useful predictor of SRM with atorvastatin, the most widely prescribed high potency statin (24). However, the association between statin use and myopathy is a class effect and if less severe SRM is pharmacological in origin, an association might be expected with common variants in SLCO1B1 or other genes related to statin disposition and muscle exposure, including those involved in drug metabolism and muscle membrane transport $(25,26)$. Thus, the possible contributions of common SNPs in a selection of these genes, together with patient specific clinical factors, were evaluated in patients treated with the highest recommended doses of simvastatin and atorvastatin in a lipid clinic based case-control study, designed to include the less severe end of the SRM spectrum (SRM2) which most commonly accounts for discontinuation of therapy in routine practice (8).

\section{RESULTS}

Characteristics of study subjects 
A total of 606 patients [ 125 cases and 481 controls], all of whom were of self-reported European ancestry were recruited into the study. The demographic and clinical characteristics of the study cohorts are summarized in Table 1. All cases reported myalgia without significant CK elevation ( $>4$ times ULN) and were classified as SRM2. One case deteriorated to SRM4 (severe myopathy) but was later diagnosed as polymyositis, not statinrelated and was therefore excluded from the data analysis. In the case group there was a significantly greater proportion of females than the control group ( $58.4 \%$ vs $44.1 \%$; $\mathrm{P}=0.004)$. A greater proportion of patients in both the case and the control groups were treated with simvastatin than atorvastatin (107 of $125,85.6 \%$ and 297 of $481,61.7 \%$ respectively; $\mathrm{P}<0.001)$. In both groups, simvastatin $40 \mathrm{mg} /$ day was the most frequently prescribed while the most common dosage regimen for atorvastatin was $80 \mathrm{mg} /$ day (Table 1). The mean age of the controls ( 60.93 years; $95 \% \mathrm{Cl}: 59.82-62.05)$ and the cases $(60.29$ years; $95 \% \mathrm{Cl}$ : 58.10 -62.48) were similar. There was no significant difference in BMI between the cases (median $28.5 \mathrm{~kg} / \mathrm{m}^{2}$, interquartile range $26.4-31.7$ ) and the controls group (median $28.5 \mathrm{~kg} / \mathrm{m}^{2}$, interquartile range $25.8-32.0$ ). There was a marked difference $(P<0.001)$ in total duration of statin treatment between the cases (median 8 months, interquartile range $3-18$ ) and the controls (median 24 months, interquartile range 12 - 65). There was no significant association between SRM and the presence of comorbidities reported to enhance the risk of SRM, such as type 2 diabetes, impaired renal function, hypothyroidism and hypertension. Approximately $17-30 \%$ of the cases and of controls reported concurrent exposure to drugs which have the potential to interact with the pharmacokinetics of statins, including fibrates, calcium antagonists and CYP3A4 inhibitors. However with the exception of warfarin (fewer patients in the case group; $p=0.008$ ) and dihydropyridine calcium antagonists (fewer patients in the control group; $p=0.031$ ) the patient-reported use of such agents was similar in cases compared to the controls. A list of all concomitant medications deemed to interact with statins which were taken by the study 
patients is provided in the supplementary Table S1. Compared to the control subjects, cases had higher concentrations of serum lipids at the time of recruitment, on maximum tolerated lipid lowering therapy, which were well above recommended treatment goals for high risk primary and secondary prevention (Table 1).

\section{Environment-gene association with SRM}

The genotype frequencies of all tested SNPs were checked for their consistency with HardyWeinberg Equilibrium (HWE) (Table 2). Frequencies for one SNP, rs1050450 in GPX1 were not in Hardy-Weinberg equilibrium and this SNP was not studied further. Of the remaining 12 SNPs studied, none were significantly different to the frequencies reported in the GBR (British in England and Scotland) derived from 1000 genomes browser (http://browser.1000genomes.org/index.html) and met the analysis criteria of having a minor allele frequency $>0.01$. Subsequently these 12 SNPs were included in further analyses. All SNPs were successfully genotyped in $99.2 \%$ of the patients (blood samples were missing for 5 individuals belonging to the control group). When these 12 SNPs were tested in dominant models (Table 2) in a univariate analysis, only the SNP in SLCO1B1 [rs4149056, (c.521T >C; V174A)] was associated with SRM $(P=0.010)$. There was a significantly higher proportion of carriers of the minor $C$ allele (heterozygotes and homozygotes) in the case group, irrespective of the type of statin used, compared to the controls; $37.6 \%$ vs $25.8 \%$ (Figure 1-A) with odds ratio (OR) of 1.73 (95\% Cl: 1.14- 2.62). There was no significant difference in the frequency of $C$ allele carriers between the simvastatin and atorvastatin intolerant cases (Figure 1-B). Polymorphisms in other genes, including SNPs in previously proposed gene candidates for SRM i.e. GATM (rs9806699) and COQ2 (rs4693075), showed no significant difference between cases and controls.

In multivariate logistic regression analyses adjusted for patient age, sex, BMI and the 11 remaining genotypes, SLCO1B1 rs4149056 (OR=1.72, 95\% Cl: 1.15- 2.59; $\mathrm{P}=0.014)$ and 
female sex $[\mathrm{OR}=1.72(95 \% \mathrm{Cl}=1.15-2.59 ; \mathrm{P}=0.006)]$ were the only variables which were independently associated with SRM (Table 3). In the statin-intolerant group the relative risk of SRM was higher in females and it increased further in patients with $C$ variant allele irrespective of sex (Table 4). In the $C$ allele carriers, the BMI was significantly lower in the cases $\left(\mathrm{N}=47\right.$, Mean BMI $\left.27.9 \mathrm{~kg} / \mathrm{m}^{2}\right)$ than the controls $\left(\mathrm{N}=123\right.$, Mean $\left.\mathrm{BMI} 29.8 \mathrm{~kg} / \mathrm{m}^{2}\right)$ a mean difference in $\mathrm{BMI}$ of $1.9 \mathrm{~kg} / \mathrm{m}^{2}(\mathrm{P}=0.02)$.

According to binary logistic regression analysis only sex $(P=0.004)$, SLCO1B1 genotype $(P=$ 0.011) and logged BMI in $C$ allele carriers $(P=0.014$,$) were found to be significantly$ associated with SRM.

\section{DISCUSSION}

A modern dilemma faced by clinicians who prescribe statins is how to decide which, if any, patients with muscle symptoms in the absence of significant CK elevation have "true" statinrelated muscle toxicity (SRM), related to the pharmacology of statins, and which have nonspecific musculoskeletal symptoms reflecting a high background prevalence in patients eligible for statin treatment. In order to determine whether pharmacological factors contribute to less severe statin-related muscle toxicity in patients referred to a specialist lipid clinic, we examined the association between SRM2-3 defined by de-challenge and rechallenge, and polymorphisms in candidate genes implicated in statin disposition and safety alongside patient demographics and clinical features. Our findings of a clear association between SRM2 and both the SLCO1B1 rs4149056 polymorphism and sex is consistent with findings reported previously in both moderate and severe cases $(9,15,18)$ which provides further evidence indicating that SRM of moderate severity is, at least in part, of pharmacological origin and appears related to altered systemic and muscular drug exposure. Therefore, the symptoms reported by patients with moderate SRM, as defined in our cohort, 
cannot be attributed solely to a "nocebo effect" or misattribution of symptoms, and imply that tailored strategies for lipid lowering therapy may reduce the risk of SRM.

Our findings of the association between female sex and SRM is in concordance with previous findings from clinical trials $(9,18)$ and epidemiological studies reporting that, female sex (linked to small body frame), along with patient age and frailty, increase susceptibility to SRM(27). In the entire study cohort, we found no association between patient age and BMI and SRM; however, the SLCO1B1 C allele carriers in the case group, irrespective of age, had a significantly lower BMI. Our data supports the view that low BMI is an endogenous risk factor for SRM $(2,28)$, perhaps because low BMI, which is linked to smaller vascular volumes and reduced muscle mass, could lead to greater statin systemic exposure, thus exacerbating the risk of SRM, particularly in the $C$ allele carriers.

Systemic exposure to statins appears to be attributable, to an extent, to the SLCO1B1 rs41490565 polymorphism resulting in altered hepatic drug uptake. It has been demonstrated that, relative to the wild-type $\pi$ genotype, homozygosity for the $C$ allele increases the area under the plasma concentration versus time (AUC) by $221 \%$ for active simvastatin acid (29), significantly more than for other statins, including pitavastatin (162\%$191 \%)$, atorvastatin (144\%), pravastatin (57 \%-130\%), rosuvastatin (62\%-117\%) and least for fluvastatin (19\%) (15). Although previous studies have shown conflicting results on the susceptibility to SRM with other statins $(11,18,20,21,30)$, there may be an increased risk for SRM among SLCO1B1 rs4149056 carriers using atorvastatin, as suggested by Pasanen and colleagues (31). Whether SLCO1B1 rs4149056 truly confers susceptibility among atorvastatin-intolerant cases remains inconclusive but the effects of the variant on the pharmacokinetics of atorvastatin (31) are certainly smaller than seen with simvastatin (32). It is also known that hepatic uptake of atorvastatin is mediated not only by OATP1B1 but also by OATP1B3 (33) and atorvastatin and its lactone appear to have lesser inhibitory effect 
on mitochondrial complex III activity (34). In the present study, we found no evidence of contributions from any of the newly proposed candidate genes toward SRM. Surprisingly, we found no association between CYP3A4*22 and SRM, even though the SNP rs35599367 has been associated with reduced CYP3A4 activity, which is involved in the metabolism of both simvastatin and atorvastatin and has been previously demonstrated to contribute to variability in simvastatin efficacy in the Dutch population (35).

In our study, patients were identified as SRM cases on the basis of having received either simvastatin or atorvastatin and discontinued treatment because of intolerable muscle symptoms which later resolved on drug withdrawal and recurred on re-challenge, without significant increase in CK. As the statin rechallenge was unblinded and often undertaken prior to referral we expect that a proportion of cases who failed rechallenge without $\mathrm{CK}$ elevation did not have true SRM as has been demonstrated by double-blind rechallenge with statins(7). While measurement of CK is recommended as a biomarker of muscle damage in symptomatic patients $(9,14,36)$ and is important for classifying SRM according to severity, it is non-specific and cannot be used alone for establishing SRM. Since CK levels during initial exposure were frequently unavailable (at the time of recruitment the majority of cases had already stopped statin therapy), we cannot exclude the possibility that the severity grading in some of our patients may have been underestimated, potentially misclassifying SRM3 or even SRM4 cases as SRM2. However, this is also likely to reflect the situation in clinic practice and although challenging, prompt measurement of CK in symptomatic patients remains of central importance for the clinical assessment of SRM.

Our study suggests that, among people of European ancestry, SLCO1B1 rs4149056 is a predisposing factor for SRM across the full spectrum of severity (SRM2 or greater) with simvastatin and atorvastatin at the highest recommended dose $(40 \mathrm{mg}$ and $80 \mathrm{mg}$ respectively). It has been proposed that the SLCO1B1 rs4149056 polymorphism may help identify patients at risk of progression to more severe statin-related myopathy. For 
simvastatin users, possession of the $C$ allele had a diagnostic sensitivity and specificity of $70.4 \%$ and $73.7 \%$, respectively, giving positive and negative likelihood ratios of 2.7 and 0.4 for the prediction of definite or incipient myopathy during 5 years of $80 \mathrm{mg} /$ day simvastatin use (37). However, in view of the low positive predictive value for progression to severe myopathy and high frequency of the $C$ allele in statin tolerant patients, in our opinion the possession of the $C$ allele is not a clinically useful diagnostic test to identify patients at risk of SRM.

In conclusion, our results demonstrate that symptoms reported by patients with SRM of moderate severity are at least in part, of pharmacological origin and cannot be attributed solely to a "nocebo effect". SLCO1B1 rs4149056 genotype is an important susceptibility factor which together with female gender, is associated with the full spectrum of SRM seen in patients treated with high doses of simvastatin and atorvastatin. However, we found no association between SRM and polymorphisms in any of the newly proposed gene candidates studied, and an accurate, predictive diagnostic test for susceptibility to SRM remains elusive. In view of their proven safety and low cost, statins will remain in clinical use for the foreseeable future. Therefore, in order to improve the already overwhelmingly positive benefit-risk ratio of statins clinicians must adopt a pragmatic approach to reduce the risk of SRM when prescribing statins, where possible avoiding the use of simvastatin which has the greatest potential for toxicity, by choosing lower initiation doses in women and other patients with lower body mass index and by avoiding co-administration of potentially interacting drugs.

\section{METHODS}

Patient recruitment, blood collection and case definitions 
Ethical approval for the study was provided by NRES Committee North East - County Durham \& Tees Valley. Patients requiring statin therapy for primary or secondary prevention of cardiovascular disease were recruited between May 2011 and October 2014 from outpatients attending the Lipid and Cardiology Clinics at the Royal Victoria Infirmary, Newcastle upon Tyne. Patients who had received a daily dose of simvastatin $40 \mathrm{mg}$ or atorvastatin $80 \mathrm{mg}$ (the two most commonly prescribed statins in our locality) for at least 6 months without new onset of muscle symptoms were defined as the statin tolerant control group. Patients who had previously received either simvastatin $40 \mathrm{mg}$ or atorvastatin $80 \mathrm{mg}$ but had discontinued the drug because of new muscle symptoms (intolerable muscle pain or weakness, with or without elevation of creatine kinase, onset within 6 months of starting therapy) which resolved on withdrawal and recurred with re-challenge at the same or a reduced dose were considered to have SRM and to be eligible for recruitment as cases. In each case the severity of muscle toxicity was graded according to the classification system based on the severity of muscle related symptoms (tolerable or intolerable) and the CK elevation (less than 4 times the upper normal limit in SRM2) proposed by Alfirevic and coworkers (8). The local laboratory reference ranges for creatine kinase were as follows: Male 10-190 U/L; Female 10-160 U/L.

After obtaining informed written consent, the medical records of those previously intolerant of simvastatin and/or atorvastatin were reviewed and a structured face-to-face interview was conducted by a trained research nurse. Patient demographics (including age, sex, height and weight), co-morbidities and medications were recorded. The indication for statin therapy, the daily doses and type of statins used and the regional distribution and temporal pattern of symptoms of muscle pain or weakness were recorded. In addition to routine serum biochemical measurements, each patient provided a venous blood sample $(4 \mathrm{ml})$ which was transferred into EDTA tubes and stored at $-80^{\circ} \mathrm{C}$ for later genotyping. 
Single nucleotide polymorphism (SNP) selection, DNA extraction and genotyping

SNPs of known functional significance were selected based on previous findings $(9,11,38-$ 42). Additionally, rs1050450 and rs713041 in glutathione peroxidases 1 and 4 (GPX1 and GPX4), respectively, were selected on the basis of decreased GPX activity associated with these SNPs reported by several previous studies (43-47) (Table 5). While there is evidence for the involvement of OATP2B1 and various multidrug resistance-associated proteins (MRPs) in transport of statins in striated muscle (48), there is no information available on the involvement of monocarboxylate transporters (MCTs), which are abundantly expressed in the skeletal muscle, and their polymorphisms in relation to SRM. We hypothesized that SRM could be promoted by the increased uptake of statins and/or accumulation of endogenous monocarboxylate metabolites (e.g. lactate) in skeletal muscle which mainly involve MCTs, possibly MCT1 and MCT4 $(25,26)$. Since there was no prior information available on the influence of either MCT1 (SLC16A1) or MCT4 (SLC16A3) gene on statinrelated myopathy, tag-SNP selection was employed for these two genes (Table 6) with tagSNPs in both MCT1 and MCT4 selected from the HapMap website (http://www.hapmap.org). The data from tagging approach from the HapMap website captured $100 \%$ of alleles with mean $r^{2} 0.994$ and 1.0, for the SLC16A1 and SLC16A3 genes, respectively.

\section{DNA extraction and genotyping}

DNA extraction was carried out using perchloric acid-chloroform extraction method as described by Daly and co-workers (49). Most SNPs were genotyped by TaqMan assays designed and supplied by Applied Biosystems in a ABI StepOne Real Time PCR system (Paisley, UK) under the following thermocycling conditions: $10 \mathrm{~min}$ at $95^{\circ} \mathrm{C}$ followed by 40 cycles of denaturation at $95^{\circ} \mathrm{C}$ for $15 \mathrm{~s}$ and annealing/extension at $60^{\circ} \mathrm{C}$ for $1 \mathrm{~min}$. Genotypes for polymorphisms in ABCC2 (rs717620) and ABCG2 (rs2231142) together with 
one SNP in SLC16A1 (rs1049434) were determined by PCR-RFLP (50) using the conditions summarized in Table 6.

\section{Sample size calculation}

Assuming a rs4149056 SLCO1B1 minor allele frequency of 0.14 in our statin-tolerant patients, we calculated that a sample size of 600 patients (500 controls and 100 cases) with $85 \%$ power would detect an OR of 2 at a significance value of 0.05 . We hypothesized that a multitude of other factors contribute to intolerance to simvastatin and atorvastatin, including clinical and environmental factors and common variants in the genes that mediate statin systemic exposure. However, as there is no priori information available on the variance in drug exposure (plasma simvastatin/atorvastatin concentration), and the quantitative effect of each genetic variant and other confounders including patient characteristics on the risk of statin muscle toxicity, we considered this sample size to be sufficient to detect any association of comparable magnitude.

\section{Statistical analysis}

Statistical analyses for all clinical parameters (expressed as mean, standard deviation, $95 \%$ confidence interval, $\mathrm{Cl}$ ) were performed using Minitab statistical software (version 16, Coventry, UK). For univariate analysis, chi-square statistics were used for categorical variables and t-tests for continuous variables. Where necessary data were log transformed to achieve normality. For multivariate analysis, by taking a dichotomous variable (cases vs controls) as dependent variable, binary logistic regression was performed to assess independent patient, clinical and genetic risk factor/s associated with the cases. Comparison of genotype frequencies for one or two variant alleles between cases vs controls was made using binary logistic regression; Hosmer and Lemeshow goodness-of-fit test was used as an indicator of the validity at the last step of iterations. A dominant model for genotypes [i.e. wild-type vs (heterozygous + homozygous genotype)] was used for all SNPs studied due to 
homozygous mutants being rare. For all analyses, a $p$-value of $<0.05$ was taken as being statistically significant.

\section{STUDY HIGHLIGHTS}

- What is the current knowledge on the topic?

The existence of an association between SLCO1B1 rs4149056 and simvastatin-induced myopathy has been demonstrated only at higher drug doses and when CK elevation is included in the definition of statin-associated musculoskeletal symptoms.

- What question did this study address?

Are statin-associated muscle symptoms without significantly raised CK levels caused by statins or are they a nocebo effect?

- What this study adds to our knowledge?

Patient-specific genetic and clinical factors associated with increased systemic exposure to statins are implicated in the full spectrum of SRM, from myalgia to severe myopathy.

- How this might change clinical pharmacology or translational science?

Pharmacological mechanisms contribute to the full spectrum of SRM including myalgia without CK elevation. A wider understanding of the predisposing factors to SRM will enable clinicians to optimize management while minimizing untoward effects in susceptible patients.

\section{ACKNOWLEDGEMENT}

We thank all the patients that took part in the study. We also thank all the research nurses (Lynn Robson, Philip Hope, Judith Coulson and Catherine Stafford), for their help with patient recruitment and Lester Rivett, for trial data management. Nur Salwani Bakar was supported by a grant from the Malaysian Ministry of Higher Education. 


\section{CONFLICT OF INTEREST/ DISCLOSURES}

The authors declare no conflict of interest.

\section{AUTHOR CONTRIBUTIONS}

NSB was involved in genetic and data analyses. DN was involved with study design and responsible for patient identification. PA was involved in study design and statistical analysis of data. CB was involved with preliminary cellular work which led to the identification and involvement of MCTs in statin transport. AKD supervised and designed the genetic analyses. FK was involved in study design and data analysis. NSB and FK drafted the manuscript. All authors were involved in redrafting of the manuscript. 


\section{REFERENCES}

(1) Chowdhury, R. et al. Adherence to cardiovascular therapy: a meta-analysis of prevalence and clinical consequences. Eur Heart J 34, 2940-8 (2013).

(2) Stroes, E.S. et al. Statin-associated muscle symptoms: impact on statin therapyEuropean Atherosclerosis Society Consensus Panel Statement on Assessment, Aetiology and Management. Eur Heart J 36, 1012-22 (2015).

(3) Zhang, H. et al. Discontinuation of statins in routine care settings: a cohort study. Annals of internal medicine 158, 526-34 (2013).

(4) Newman, C.B. \& Tobert, J.A. Statin intolerance: reconciling clinical trials and clinical experience. JAMA 313, 1011-2 (2015).

(5) Collins, R. et al. Interpretation of the evidence for the efficacy and safety of statin therapy. Lancet 388, 2532-61 (2016).

(6) Moriarty, P.M. et al. Efficacy and safety of alirocumab vs ezetimibe in statinintolerant patients, with a statin rechallenge arm: The ODYSSEY ALTERNATIVE randomized trial. Journal of clinical lipidology 9, 758-69 (2015).

(7) Nissen, S.E. et al. Efficacy and Tolerability of Evolocumab vs Ezetimibe in Patients With Muscle-Related Statin Intolerance: The GAUSS-3 Randomized Clinical Trial. Jama 315, 1580-90 (2016).

(8) Alfirevic, A. et al. Phenotype standardization for statin-induced myotoxicity. Clin Pharmacol Ther 96, 470-6 (2014).

(9) Link, E. et al. SLCO1B1 variants and statin-induced myopathy--a genomewide study. The New England journal of medicine 359, 789-99 (2008).

(10) Schech, S. et al. Risk factors for statin-associated rhabdomyolysis. Pharmacoepidemiol Drug Saf 16, 352-8 (2007).

(11) Puccetti, L., Ciani, F. \& Auteri, A. Genetic involvement in statins induced myopathy. Preliminary data from an observational case-control study. Atherosclerosis 211, 289 (2010).

(12) Ho, P.M. et al. Medication nonadherence is associated with a broad range of adverse outcomes in patients with coronary artery disease. American heart journal 155, 772-9 (2008).

(13) Feng, Q., Wilke, R.A. \& Baye, T.M. Individualized risk for statin-induced myopathy: current knowledge, emerging challenges and potential solutions.

Pharmacogenomics 13, 579-94 (2012).

(14) Pasternak, R.C., Smith, S.C., Jr., Bairey-Merz, C.N., Grundy, S.M., Cleeman, J.I. \& Lenfant, C. ACC/AHA/NHLBI Clinical Advisory on the Use and Safety of Statins. Circulation 106, 1024-8 (2002).

(15) Wilke, R.A. et al. The clinical pharmacogenomics implementation consortium: CPIC guideline for SLCO1B1 and simvastatin-induced myopathy. Clin Pharmacol Ther 92, 112-7 (2012).

(16) Mosshammer, D., Schaeffeler, E., Schwab, M. \& Morike, K. Mechanisms and assessment of statin-related muscular adverse effects. British journal of clinical pharmacology 78, 454-66 (2014).

(17) Pasanen, M.K., Neuvonen, M., Neuvonen, P.J. \& Niemi, M. SLCO1B1 polymorphism markedly affects the pharmacokinetics of simvastatin acid. Pharmacogenetics and genomics 16, 873-9 (2006).

(18) Voora, D. et al. The SLCO1B1*5 genetic variant is associated with statin-induced side effects. J Am Coll Cardiol 54, 1609-16 (2009). 
(19) Donnelly, L.A. et al. Common nonsynonymous substitutions in SLCO1B1 predispose to statin intolerance in routinely treated individuals with type 2 diabetes: a goDARTS study. Clin Pharmacol Ther 89, 210-6 (2011).

(20) Brunham, L.R. et al. Differential effect of the rs4149056 variant in SLCO1B1 on myopathy associated with simvastatin and atorvastatin. The Pharmacogenomics Journal 12, 233-7 (2012).

(21) Carr, D.F. et al. SLCO1B1 genetic variant associated with statin-induced myopathy: a proof-of-concept study using the clinical practice research datalink. Clin Pharmacol Ther 94, 695-701 (2013).

(22) Hou, Q., Li, S., Li, L., Li, Y., Sun, X. \& Tian, H. Association Between SLCO1B1 Gene T521C Polymorphism and Statin-Related Myopathy Risk: A Meta-Analysis of CaseControl Studies. Medicine 94, e1268 (2015).

(23) Hubacek, J.A. et al. SLCO1B1 polymorphism is not associated with risk of statininduced myalgia/myopathy in a Czech population. Medical science monitor : international medical journal of experimental and clinical research 21, 1454-9 (2015).

(24) Talameh, J.A. \& Kitzmiller, J.P. Pharmacogenetics of Statin-Induced Myopathy: A Focused Review of the Clinical Translation of Pharmacokinetic Genetic Variants. Journal of pharmacogenomics \& pharmacoproteomics 5, (2014).

(25) Juel, C. \& Halestrap, A.P. Lactate transport in skeletal muscle - role and regulation of the monocarboxylate transporter. J Physiol 517 ( Pt 3), 633-42 (1999).

(26) Pilegaard, H., Terzis, G., Halestrap, A. \& Juel, C. Distribution of the lactate/H+ transporter isoforms MCT1 and MCT4 in human skeletal muscle. Am J Physiol 276, E843-8 (1999).

(27) Armitage, J. The safety of statins in clinical practice. Lancet 370, 1781-90 (2007).

(28) Mancini, G.B. et al. Diagnosis, prevention, and management of statin adverse effects and intolerance: Canadian Working Group Consensus update. Can J Cardiol 29, 1553-68 (2013).

(29) Pasanen, M.K., Miettinen, T.A., Gylling, H., Neuvonen, P.J. \& Niemi, M. Polymorphism of the hepatic influx transporter organic anion transporting polypeptide 1B1 is associated with increased cholesterol synthesis rate. Pharmacogenetics and genomics 18, 921-6 (2008).

(30) Santos, P.C. et al. SLCO1B1 haplotypes are not associated with atorvastatin-induced myalgia in Brazilian patients with familial hypercholesterolemia. European journal of clinical pharmacology 68, 273-9 (2012).

(31) Pasanen, M.K., Fredrikson, H., Neuvonen, P.J. \& Niemi, M. Different effects of SLCO1B1 polymorphism on the pharmacokinetics of atorvastatin and rosuvastatin. Clinical pharmacology and therapeutics 82, 726-33 (2007).

(32) Pasanen, M.K., Backman, J.T., Neuvonen, P.J. \& Niemi, M. Frequencies of single nucleotide polymorphisms and haplotypes of organic anion transporting polypeptide 1B1 SLCO1B1 gene in a Finnish population. European journal of clinical pharmacology 62, 409-15 (2006).

(33) Vildhede, A. et al. Hepatic uptake of atorvastatin: influence of variability in transporter expression on uptake clearance and drug-drug interactions. Drug metabolism and disposition: the biological fate of chemicals 42, 1210-8 (2014).

(34) Schirris, T.J. et al. Statin-Induced Myopathy Is Associated with Mitochondrial Complex III Inhibition. Cell metabolism 22, 399-407 (2015).

(35) Elens, L. et al. Novel CYP3A4 intron 6 single nucleotide polymorphism is associated with simvastatin-mediated cholesterol reduction in the Rotterdam Study. Pharmacogenet Genomics 21, 861-6 (2011). 
(36) Thompson, P.D., Clarkson, P.M. \& Rosenson, R.S. An Assessment of Statin Safety by Muscle Experts. The American Journal of Cardiology 97, 69C-76C. (2006).

(37) Stewart, A. SLCO1B1 Polymorphisms and Statin-Induced Myopathy. PLoS Curr 5, (2013).

(38) Becker, M.L. et al. Genetic variation in the ABCC2 gene is associated with dose decreases or switches to other cholesterol-lowering drugs during simvastatin and atorvastatin therapy. The pharmacogenomics journal 13, 251-6 (2013).

(39) Elens, L., van Gelder, T., Hesselink, D.A., Haufroid, V. \& van Schaik, R.H. CYP3A4*22: promising newly identified CYP3A4 variant allele for personalizing pharmacotherapy. Pharmacogenomics 14, 47-62 (2013).

(40) Keskitalo, J.E., Kurkinen, K.J., Neuvoneni, P.J. \& Niemi, M. ABCB1 haplotypes differentially affect the pharmacokinetics of the acid and lactone forms of simvastatin and atorvastatin. Clinical pharmacology and therapeutics 84, 457-61 (2008).

(41) Mangravite, L.M. et al. A statin-dependent QTL for GATM expression is associated with statin-induced myopathy. Nature 502, 377-80 (2013).

(42) Tsamandouras, N. et al. Identification of the effect of multiple polymorphisms on the pharmacokinetics of simvastatin and simvastatin acid using a populationmodeling approach. Clinical pharmacology and therapeutics 96, 90-100 (2014).

(43) Blein, S. et al. Factors associated with oxidative stress and cancer risk in the Breast and Prostate Cancer Cohort Consortium. Free Radic Res 48, 380-6 (2014).

(44) Gautrey, H., Nicol, F., Sneddon, A.A., Hall, J. \& Hesketh, J. A T/C polymorphism in the GPX4 3'UTR affects the selenoprotein expression pattern and cell viability in transfected Caco-2 cells. Biochim Biophys Acta 1810, 584-91 (2011).

(45) Hong, Z., Tian, C. \& Zhang, X. GPX1 gene Pro200Leu polymorphism, erythrocyte GPX activity, and cancer risk. Mol Biol Rep 40, 1801-12 (2013).

(46) Larsen, S. et al. Simvastatin effects on skeletal muscle: Relation to decreased mitochondrial function and glucose intolerance. Journal of the American College of Cardiology 61, 44-53 (2013).

(47) Men, T. et al. The rs $1050450 \mathrm{C}>$ T polymorphism of GPX1 is associated with the risk of bladder but not prostate cancer: evidence from a meta-analysis. Tumour Biol 35, 269-75 (2014).

(48) Knauer, M.J. et al. Human skeletal muscle drug transporters determine local exposure and toxicity of statins. Circ Res 106, 297-306 (2010).

(49) Daly, A.K., Monkman, S.C., Smart, J., Steward, A. \& Cholerton, S. Analysis of cytochrome P450 polymorphisms. Methods Mol Biol 107, 405-22 (1998).

(50) Daly, A.K., Aithal, G.P., Leathart, J.B., Swainsbury, R.A., Dang, T.S. \& Day, C.P. Genetic susceptibility to diclofenac-induced hepatotoxicity: contribution of UGT2B7, CYP2C8, and ABCC2 genotypes. Gastroenterology 132, 272-81 (2007). 


\section{FIGURE LEGEND}

Figure 1: Distribution of SLCO1B1 rs4149056 genotype between cases and controls (A) and between simvastatin and atorvastatin users in the case group (B)

\section{SUPPLEMENTARY FILE LEGEND}

Supplementary Table S1: Proportion of patients taking drugs known to interact with statins 
A

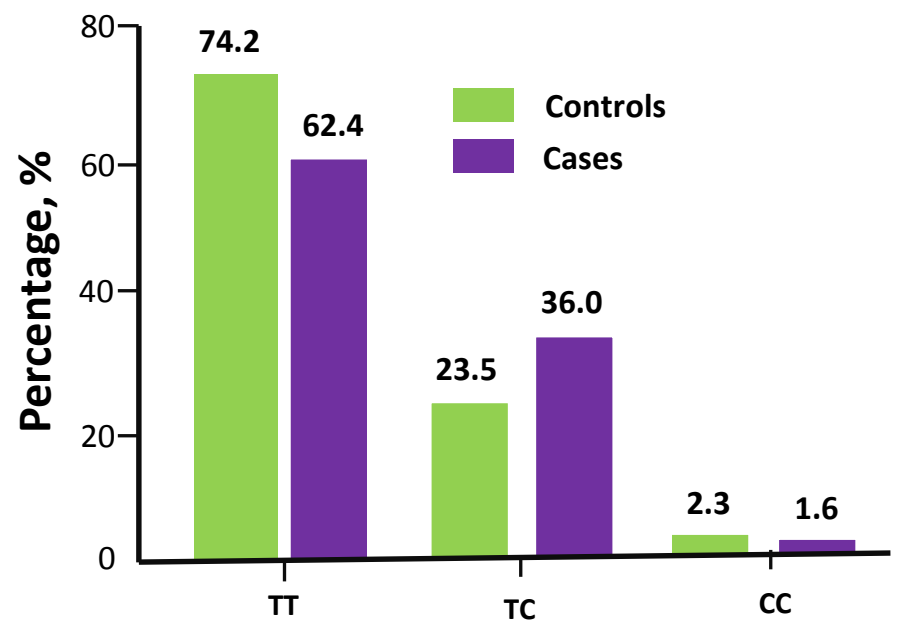

B

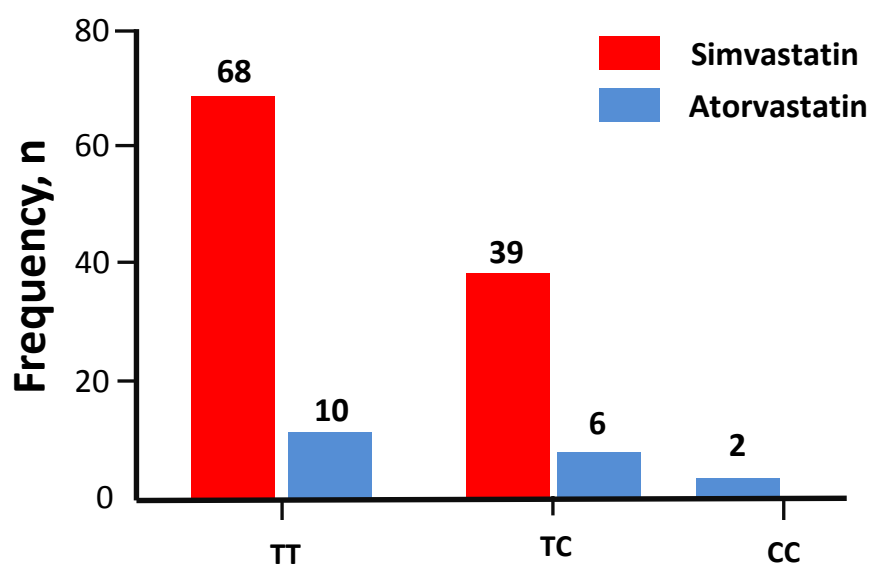


Table S1: Proportion of patients taking drugs known to interact with statins

\begin{tabular}{lcc}
\hline Drug & Control; $\mathbf{n}(\%)$ & Cases; $\mathbf{n}$ (\%) \\
\hline Amiodarone & $1(0.2)$ & $0(0.0)$ \\
Ciclosporin & $0(0.0)$ & $0(0.0)$ \\
Colchicine & $0(0.0)$ & $2(1.6)$ \\
Azithromycin & $2(0.4)$ & $0(0.0)$ \\
Clarithromycin & $0(0.0)$ & $0(0.0)$ \\
Erythromycin & $1(0.2)$ & $0(0.0)$ \\
Digoxin & $9(1.9)$ & $1(0.8)$ \\
Amlodipine & $29(6.0)$ & $14(11.2)$ \\
Lercanidipine & $4(0.8)$ & $1(0.8)$ \\
Diltiazem & $4(0.8)$ & $2(1.6)$ \\
Nifedipine & $3(0.6)$ & $2(1.6)$ \\
Verapamil & $2(0.4)$ & $1(0.8)$ \\
Ezetimibe & $29(6.0)$ & $8(6.4)$ \\
Bezafibrate & $0(0.0)$ & $1(0.8)$ \\
Fenofibrate & $23(4.8)$ & $2(1.6)$ \\
Itraoconazole & $0(0.0)$ & $0(0.0)$ \\
Ketoconazole & $0(0.0)$ & $0(0.0)$ \\
Terbinafine & $0(0.0)$ & $0(0.0)$ \\
Sildenafil & $1(0.2)$ & $1(0.8)$ \\
Warfarin & $51(10.6)$ & $3(2.4)$ \\
PPI (-prazole) & $138(28.7)$ & $19(15.2)$ \\
Total & $159(33.1)$ & $37(29.6)$ \\
\hline
\end{tabular}


Table 1: Demographic and clinical characteristics of statin-tolerant (controls) and statin-intolerant (cases) subjects

\begin{tabular}{|c|c|c|c|}
\hline Variables & $\begin{array}{l}\text { Controls } \\
(n=481)\end{array}$ & $\begin{array}{l}\text { Cases } \\
(n=125)\end{array}$ & P-value \\
\hline Sex & & & 0.004 \\
\hline $\begin{array}{l}\text { Female, N (\%) } \\
\text { Male, N (\%) }\end{array}$ & $\begin{array}{l}212(44.1 \%) \\
269(55.9 \%)\end{array}$ & $\begin{array}{l}73(58.4 \%) \\
52(41.6 \%)\end{array}$ & \\
\hline Age at enrolment (years), mean (95 \% Cl) & $60.9(59.8-62.1)$ & $60.3(58.1-62.5)$ & 0.610 \\
\hline Body mass index $\left(\mathrm{kg} / \mathrm{m}^{2}\right)$, median (LQ, UQ) & $\begin{array}{l}28.5(25.8 \\
32.0)\end{array}$ & $\begin{array}{l}28.5(26.4 \\
31.7)\end{array}$ & 0.933 \\
\hline Duration on statin (months), median (LQ, UQ) & $24(12,65)$ & $8(3,18)$ & $<0.001$ \\
\hline Statin, N (\%) & & & $<0.001$ \\
\hline $\begin{array}{l}\text { Simvastatin, } \\
10 \mathrm{mg} / \text { day } \\
20 \mathrm{mg} / \text { day } \\
40 \mathrm{mg} / \text { day } \\
80 \mathrm{mg} / \text { day }\end{array}$ & $\begin{array}{l}297(61.9) \\
- \\
4(1.3) \\
286(96.3) \\
7(2.4)\end{array}$ & $\begin{array}{l}107^{¥}(85.6) \\
8(7.5) \\
15(14.0) \\
78(72.9) \\
4(3.7)\end{array}$ & \\
\hline $\begin{array}{l}\text { Atorvastatin, } \\
10 \mathrm{mg} / \text { day } \\
20 \mathrm{mg} / \text { day } \\
30 \mathrm{mg} / \text { day } \\
40 \mathrm{mg} / \text { day } \\
80 \mathrm{mg} / \text { day }\end{array}$ & $\begin{array}{l}183(38.2) \\
1(0.5) \\
2(1.1) \\
1(0.5) \\
12(6.6) \\
167(91.3)\end{array}$ & $\begin{array}{l}18^{\#}(14.4) \\
1(5.6) \\
- \\
- \\
1(5.6) \\
15(83.3)\end{array}$ & \\
\hline \multicolumn{4}{|l|}{ Plasma lipids, mean ( \pm SD) } \\
\hline $\begin{array}{l}\text { Cholesterol, } \mathrm{mmol} / \mathrm{L} \\
\text { Triglyceride, } \mathrm{mmol} / \mathrm{L} \\
\text { HDL-cholesterol, } \mathrm{mmol} / \mathrm{L}\end{array}$ & $\begin{array}{l}4.62(1.72) \\
1.85(1.46) \\
1.45(0.45)\end{array}$ & $\begin{array}{l}6.45(1.71) \\
2.28(1.49) \\
1.48(0.44)\end{array}$ & $\begin{array}{l}<0.001 \\
<0.001 \\
0.852\end{array}$ \\
\hline \multicolumn{4}{|l|}{ Other medical conditions, N (\%) } \\
\hline $\begin{array}{l}\text { Type } 2 \text { Diabetes } \\
\text { Hypertension } \\
\text { Hypothyroidism } \\
\text { Chronic Kidney Disease 3A } \\
\text { Chronic Kidney Disease 3B-5 } \\
\text { None }\end{array}$ & $\begin{array}{l}53(11.0) \\
123(25.6) \\
28(5.8) \\
35(7.3) \\
32(6.7) \\
70(14.6)\end{array}$ & $\begin{array}{l}8(6.4) \\
35(28.0) \\
11(8.8) \\
5(4.0) \\
3(2.4) \\
20(16)\end{array}$ & $\begin{array}{l}0.196 \\
0.543 \\
0.216 \\
0.249 \\
0.097 \\
0.617\end{array}$ \\
\hline $\begin{array}{l}\text { Statin interacting drugs, } \mathrm{N}(\%) \\
\text { Digoxin } \\
\text { Fibrates } \\
\text { CYP3A4 inhibitor } \\
\text { Calcium antagonist (dihydropyridine) } \\
\text { Calcium antagonist (non-dihydropyridine) } \\
\text { Aspirin } \\
\text { Warfarin } \\
\text { Ezetimibe } \\
\text { Sildenafil }\end{array}$ & $\begin{array}{l}9(1.9) \\
24(5.0) \\
3(0.6) \\
36(7.4) \\
6(1.2) \\
148(30.7) \\
51(10.6) \\
29(6.0) \\
1(0.2)\end{array}$ & $\begin{array}{l}2(1.6) \\
4(3.2) \\
0(0) \\
17(13.4) \\
3(2.4) \\
27(21.6) \\
3(2.4) \\
8(6.4) \\
1(0.8)\end{array}$ & $\begin{array}{l}0.839 \\
0.396 \\
- \\
0.031 \\
0.342 \\
0.129 \\
0.008 \\
0.877 \\
0.303\end{array}$ \\
\hline
\end{tabular}

* Initiation dose could not be confirmed for two individuals

\#Initiation dose could not be confirmed for one individual 
Table 2: Association between individual SNPs and SRM by univariate analysis

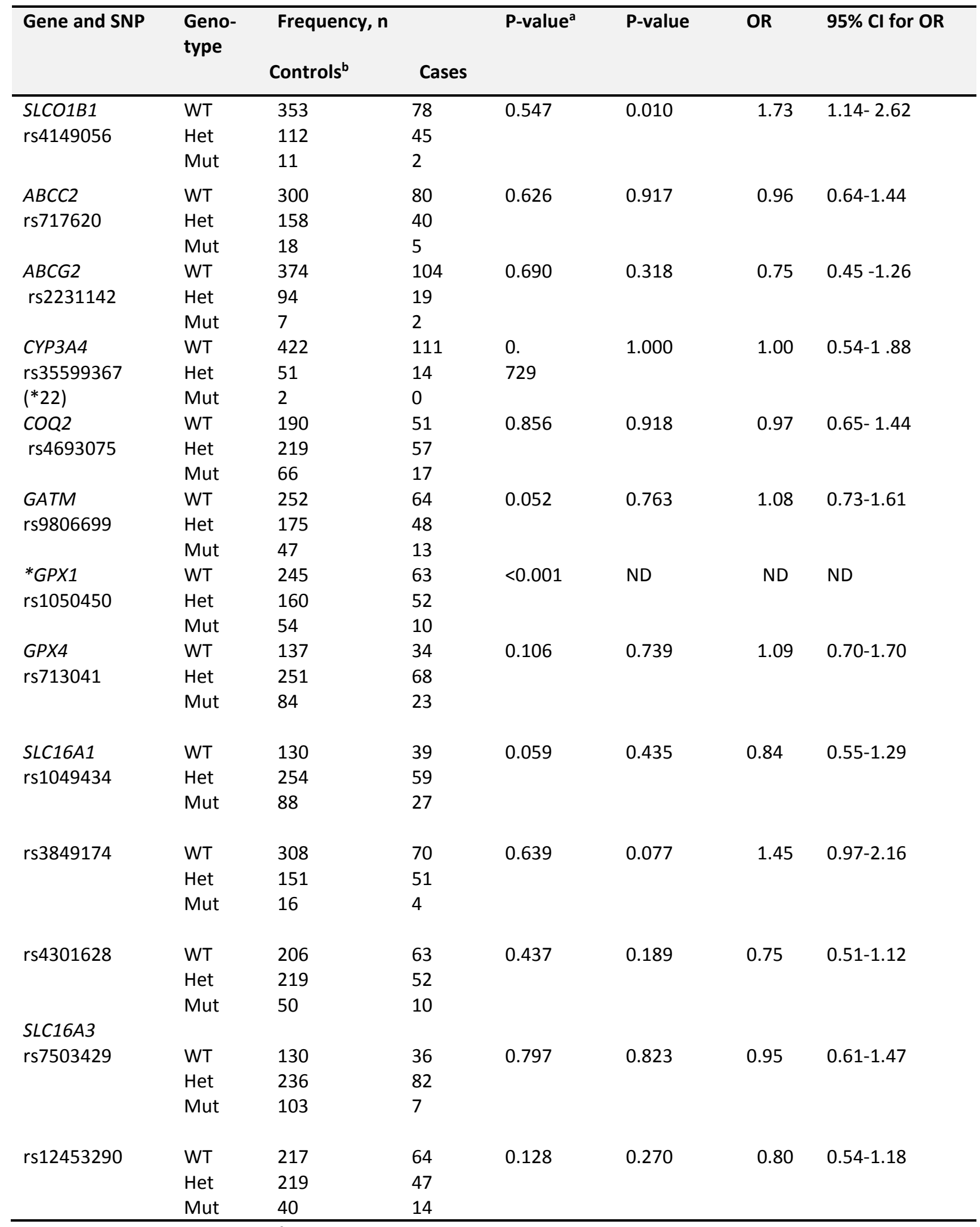

*The rs1050450 SNP was excluded from subsequent analyses.

a P-value for HWE calculated in control group and compared with CEU population.

${ }^{b}$ Genotype results for all the SNPs investigated were unavailable for 5 individuals from control group.

WT; wild type, Het; Heterozygous genotype, Mut; Homogenous mutants, OR; Odds ratio, ND; not determined. 
Table 3: Association between patient sex, rs4149056 SNP and SRM (adjusted for patient age, sex, $\mathrm{BMI}$ and other 11 genotypes) according to binary logistic regression analysis

\begin{tabular}{|c|c|c|c|c|c|c|}
\hline $\begin{array}{l}\text { Dependent } \\
\text { Variables }\end{array}$ & Controls & Cases & Explanatory variables & P-value & OR & $\begin{array}{l}95 \% \mathrm{Cl} \text { for } \\
\text { ORף }\end{array}$ \\
\hline $\begin{array}{l}\text { Statin-related } \\
\text { muscle } \\
\text { toxicity }\end{array}$ & $481^{*}$ & $125^{*}$ & $\begin{array}{l}\text { Patient sex } \\
\text { SLCO1B1 (rs4149056) } \\
\text { ABCC2 (rs717620) } \\
\text { ABCG2 (rs2231142) } \\
\text { CYP3A4*22 (rs35599367) } \\
\text { COQ2 (rs4693075) } \\
\text { GATM (rs9806699) } \\
\text { GPX4 (rs703041) } \\
\text { SLC16A1(rs1049434) } \\
\text { SLC16A1(rs3849174) } \\
\text { SLC16A1 (rs4301628) } \\
\text { SLC16A4 (rs7503429) } \\
\text { SLC16A4 (rs12453290) }\end{array}$ & $\begin{array}{l}0.006 \\
0.014 \\
0.800 \\
0.228 \\
0.884 \\
0.837 \\
0.747 \\
0.733 \\
0.456 \\
0.121 \\
0.406 \\
0.990 \\
0.310\end{array}$ & $\begin{array}{l}1.72 \\
1.66 \\
0.96 \\
0.74 \\
0.98 \\
0.98 \\
1.03 \\
1.09 \\
0.83 \\
1.29 \\
0.80 \\
0.95 \\
0.81\end{array}$ & $\begin{array}{c}1.15-2.59 \\
1.08-2.54 \\
0.64-1.49 \\
0.44-1.25 \\
0.52-1.86 \\
0.65-1.48 \\
0.68-1.54 \\
0.69-1.70 \\
0.49-1.44 \\
0.78-2.04 \\
0.49-1.33 \\
0.61-1.51 \\
0.54-1.22\end{array}$ \\
\hline
\end{tabular}

* Genotypes from 6 individuals ( 5 in controls and 1 case) were not included in the analysis.

\# P-value for comparison of genotypes frequencies possession of one or two variant alleles between cases vs controls

I) Odds ratio describes the odds to be a case relative to a control when having at least one variant allele (or being female). 
Table 4: The relative risk of SRM in male and female SLCO1B1 rs4149056 carriers (TC+CC genotypes) compared to wild-type (TT genotype) and wild-type female compared to male ( $T T$ genotype)

\begin{tabular}{llll}
\hline Category & OR & $95 \% \mathrm{Cl}$ & P-value \\
\hline Male $(T C+C C)$ vs male TT genotypes & 2.43 & $1.3140,4.4843$ & 0.0046 \\
Female $(T C+C C)$ vs female TT genotypes & 2.93 & $1.5847,5.4279$ & 0.0006 \\
Female TT vs Male TT genotype & 2.25 & $1.3550,3.7212$ & 0.0017 \\
\hline
\end{tabular}


Table 5: SNPs selected for genotyping on the basis of previous genotyping studies on SRM

\begin{tabular}{|c|c|c|c|}
\hline Gene & SNP & $\begin{array}{l}\text { Evidence of the association with SRM/ } \\
\text { reason for the selection }\end{array}$ & Reference(s) \\
\hline SLCO1B1 & rs4149056 & $\begin{array}{l}\text { Encodes a liver-specific member of the } \\
\text { organic anion transporter family. The protein } \\
\text { is involved in the removal of drug } \\
\text { compounds such as statins. OR for SRM = } \\
4.5 \text {. }\end{array}$ & $(9,18)$ \\
\hline$A B C C 2$ & rs717620 & $\begin{array}{l}\text { Protein encoded by this gene is included in } \\
\text { the superfamily of ATP-binding cassette } \\
\text { (ABC) transporters. ABC proteins transport } \\
\text { various molecules across extra- and intra- } \\
\text { cellular membranes. Associated with } \\
\text { switches to other cholesterol-lowering drugs } \\
\text { during simvastatin therapy. }\end{array}$ & (38) \\
\hline$A B C G 2$ & rs2231142 & $\begin{array}{l}\text { Protein encoded by this gene is included in } \\
\text { the superfamily of ATP-binding cassette } \\
\text { (ABC) transporters. ABC proteins transport } \\
\text { various molecules across extra- and intra- } \\
\text { cellular membranes. Polymorphism markedly } \\
\text { affects PKs of simvastatin acid. }\end{array}$ & $(40,42)$ \\
\hline СYРЗА4 & $\begin{array}{l}\text { rs35599367 } \\
(* 22 \text { allele) }\end{array}$ & $\begin{array}{l}\text { Encodes a member of the cytochrome P450 } \\
\text { superfamily of enzymes. The cytochrome } \\
\text { P450 proteins are monooxygenases that } \\
\text { catalyze many reactions involved in drug } \\
\text { metabolism and synthesis of cholesterol, } \\
\text { steroids and other lipids. Associated with } \\
\text { statin metabolism and response. }\end{array}$ & $(35,39,42)$ \\
\hline COQ2 & rs4693075 & $\begin{array}{l}\text { Encodes an enzyme that functions in the } \\
\text { final steps in the biosynthesis of } \mathrm{CoQ} \\
\text { (ubiquinone), a redox carrier in the } \\
\text { mitochondrial respiratory chain and a lipid- } \\
\text { soluble antioxidant. Polymorphism } \\
\text { associated with statin intolerance and } \\
\text { myopathy. }\end{array}$ & (11) \\
\hline GATM & rs9806699 & $\begin{array}{l}\text { Gene encodes a mitochondrial enzyme that } \\
\text { belongs to the amidinotransferase family. } \\
\text { The enzyme is involved in creatine } \\
\text { biosynthesis. Meta-analysis odds ratio for } \\
\text { SRM for this polymorphism }=0.60\end{array}$ & (41) \\
\hline SLC16A1 & rs9429505 & $\begin{array}{l}\text { Encodes for the monocarboxylate } \\
\text { transporter (MCT1) which is abundantly } \\
\text { expressed in the membrane of striated } \\
\text { muscle. }\end{array}$ & (26) \\
\hline SLC16A3 & rs7503429 & $\begin{array}{l}\text { Encodes for the monocarboxylate } \\
\text { transporter (MCT4) which is abundantly } \\
\text { expressed in the membrane of striated } \\
\text { muscle. }\end{array}$ & (26) \\
\hline
\end{tabular}


Table 6 : Tag SNPs in SLC16A1 and SLC16A3 genes selected for genotyping and the primers, PCR conditions and restriction enzymes used for ABCC2 (rs717620), ABCG2 (rs2231142) and SLC16A1 (rs1049434) genotyping by PCR-RFLP

\begin{tabular}{|c|c|c|c|c|c|c|c|}
\hline Gene & Test & $\begin{array}{l}\text { Alleles } \\
\text { captured }\end{array}$ & Assay & Primer set & PCR conditionsๆ & $\begin{array}{c}\text { PCR } \\
\text { product } \\
\text { (bp) }\end{array}$ & $\begin{array}{r}\text { Restriction enzyme } \\
\text { (Recognition site) }\end{array}$ \\
\hline \multirow[t]{3}{*}{$\begin{array}{l}\text { SLC16A1 } \\
\text { (MCT1) }\end{array}$} & rs9429505 & $\begin{array}{l}\text { rs7552903, } \\
\text { rs4839272, } \\
\text { rs2149036, } \\
\text { rs4839270, } \\
\text { rs3849174, } \\
\text { rs7536532, } \\
\text { rs9429505, } \\
\text { rs } 7518984\end{array}$ & \multirow[t]{2}{*}{$\begin{array}{l}A B C C 2 \\
\text { rs717620 }\end{array}$} & \multirow[t]{2}{*}{$\begin{array}{l}\text { Forward } \\
\text { 5'-TGTCCATCCACTGTTTCAATG - 3' } \\
\text { Reverse } \\
\text { 5'-CTGGACTGCGTCTGGATC- 3' }\end{array}$} & \multirow[t]{2}{*}{ Annealing at $54^{\circ} \mathrm{C}$ for $1 \mathrm{~min}$} & \multirow[t]{2}{*}{193} & \multirow[t]{2}{*}{ Taql (TCGA) } \\
\hline & rs7556664 & $\begin{array}{l}\text { rs3789592, } \\
\text { rs7169, } \\
\text { rs1049434, } \\
\text { rs6537765, } \\
\text { rs7556664 }\end{array}$ & & & & & \\
\hline & rs12028967 & $\begin{array}{l}\text { rs4301628, } \\
\text { rs12028967 }\end{array}$ & $\begin{array}{l}A B C G 2 \\
\text { rs2231142 }\end{array}$ & $\begin{array}{l}\text { Forward } \\
\text { 5'- GTCTCATTAA AATGCTATTT - 3' } \\
\text { Reverse } \\
\text { 5'- CTCTTGAATG ACCCTGTTGA - 3' }\end{array}$ & $\begin{array}{l}\text { Annealing at } 50^{\circ} \mathrm{C} \text { for } 35 \\
\text { sec }\end{array}$ & 151 & Msel (TTAA) \\
\hline $\begin{array}{l}\text { SLC16A3 } \\
\text { (MCT4) }\end{array}$ & $\begin{array}{l}\text { rs7503429 } \\
\text { rs12453290 }\end{array}$ & $\begin{array}{l}\text { rs7503429 } \\
\text { rs12453290 }\end{array}$ & $\begin{array}{l}\text { SLC16A1 } \\
\text { rs1049434 }\end{array}$ & $\begin{array}{l}\text { Forward } \\
\text { 5'- TCAATGAACAACTGGTATGA- 3' } \\
\text { Reverse } \\
\text { 5'- ATGGAGACTACAAATACACA-3' }\end{array}$ & Annealing at $55^{\circ} \mathrm{C}$ for $1 \mathrm{~min}$ & 387 & $\operatorname{Bccl}($ CCATC) \\
\hline
\end{tabular}

SNPs in bold text were chosen for genotyping based upon MAF $>0.20$ value obtained from 1958 British birth cohort website http://www.b58cgene.sgul.ac.uk/.

IApart from the annealing temperatures described above, all PCR assays involved 35 cycles, with denaturation at $94^{\circ} \mathrm{C}$ for 1 min, extension at $72^{\circ} \mathrm{C}$ for 1 $\mathrm{min}$ and were held in the last cycle at $72{ }^{\circ} \mathrm{C}$ for $7 \mathrm{~min}$ to ensure elongation except for rs2231142. For rs 2231142 , the period for each step in each cycle was $35 \mathrm{sec}$ instead of $1 \mathrm{~min}$. The ABCG2 and SLC16A1 assays were developed for this project. The ABCC2 assay was described previously (42). 